\title{
Stakeholders' Level of Awareness and Acceptance of the Bataan Peninsula State University College of Nursing and Midwifery Goals and Objectives: Traversing to the Realization of the University's Vision and Mission
}

Ronnell D Dela Rosa* and Norma R Pantaleon

College of Nursing and Midwifery, Bataan Peninsula State University, Philippines

\begin{abstract}
Nursing Graduates of the Bataan Peninsula State University may probably recite genuinely by heart the vision and mission statement of their Alma matter for the Bachelor of Science in Nursing Degree as they articulate the College Goals and Objectives in the current professional affiliations. But if someone asked what transpire them to the engagement of the professional works into the delivery of quality graduates of nursing may give them a feeling apprehension that these goals and objectives of their program may not be well articulated. This attempt of exploring the level awareness and acceptance to the new Vision and Mission of the Bataan Peninsula State University would engage them in understanding the old and the new proposal for the college goals and objectives. Thus, providing traverse journey on realizing the vision and mission of the university. The study recommends that continuous recruitment in the analysis of the stakeholders perspectives most especially the alumni as it has been established since 1990's that it must be routinely reviewed and strengthen the contact between alumni thru college activities like extensions and research works. Likewise, students and faculty members must be able to experience in their learning in particular to their curriculum that the VMGO must be evident using the new framework of outcomes based education. For the industry partners, the job descriptions, duties and responsibilities sin incorporation this in their standards of work may be considered. University personnel especially the administrative department must give full support in the financial assistance to deploy this endeavor of disseminating strongly the college VMGO. Lastly the adopted communities must be given a good avenue for them to well learn the VMGO and live with it. A focused group discussion may helpful to assert their knowledge.
\end{abstract}

Keywords: Nursing graduates; Vision and mission; College goals; Objectives

\section{Introduction}

Nursing Graduates of the Bataan Peninsula State University may probably recite genuinely by heart the vision and mission statement of their Alma matter for the Bachelor of Science in Nursing Degree as they articulate the College Goals and Objectives in the current professional affiliations. But if someone asked what transpire them to the engagement of the professional works into the delivery of quality graduates of nursing may give them a feeling apprehension that these goals and objectives of their program may not be well articulated. This attempt of exploring the level awareness and acceptance to the new Vision and Mission of the Bataan Peninsula State University would engage them in understanding the old and the new proposal for the college goals and objectives. Thus, providing traverse journey on realizing the vision and mission of the university [1].

May be not right away. It takes effort to identify your ultimate goals and objectives in their current affiliation, but imagining a bigger picture of how they could be living professionally. That's what the process of creating a topline strategy for the college as alumni and stakeholders of the program offerings. This study had explored the impact on the professional graduates' affiliations and their level of awareness and acceptance on the College Goals and Objectives by its stakeholders including alumni, students, faculty members, industry partners like the Bataan General Hospitals, Mariveles Mental Hospitals, Private Hospitals, District Hospitals, Rural Health Units, Industrial Companies and stakeholders outside the Province of Bataan. Also, the VMGO had been articulated in realization with the community partners of the College like in the Provincial Jail of the Bataan, and other far flung community settings where the College had been immersing for the past years.
In compliance with University Memorandum No. 0130 series of 2016, members of the Technical Working Group for the BPSU VMGOs Review and Revision convened last February 12, 2016 at the Quality Assurance Office, BPSU Main Campus, City of Balanga, and Bataan. The group had decided to further assess the BPSU VMGO in terms of the level of awareness and status of acceptability of the different members of the academic community as one of the basis for possible revision. In this localized rationale, the College of Nursing and Midwifery had recreated a technical working group for this study to assess impact of the College Goals and Objectives in the professional affiliations of the nursing graduates.

The study had gathered data among stakeholders of the college of nursing and midwifery. An informed consent was secured and interviewed were facilitated. Privacy and anonymity in answering the questionnaire and interview guided questions were delivered. In recruiting samples, convenience samples were considered.

The instrument was adapted using a four point rating scale from the previous study conducted on VMGO and was modified to fit the

*Corresponding author: Ronnell D Dela Rosa, Elected President, College of Nursing and Midwifery, Bataan Peninsula State University, Philippines, Tel: +0472372350; E-mail: drronnelldelarosa@gmail.com

Received October 17, 2018; Accepted October 26, 2018; Published November 02, 2018

Citation: Rosa RDD, Pantaleon NR (2018) Stakeholders' Level of Awareness and Acceptance of the Bataan Peninsula State University College of Nursing and Midwifery Goals and Objectives: Traversing to the Realization of the University's Vision and Mission. J Health Educ Res Dev 6: 280. doi: 10.4172/2380-5439.1000280

Copyright: () 2018 Rosa RDD, et al. This is an open-access article distributed under the terms of the Creative Commons Attribution License, which permits unrestricted use, distribution, and reproduction in any medium, provided the original author and source are credited. 
parameters and indicators of the outcomes-based instrument of AACCUP.

\section{Part I. Assessment of the BPSU vision and mission and college of nursing and midwifery goals and objectives as perceived by the university employees and students}

Table 1 provides the profile of the respondents on the assessment of the Awareness and Acceptability of the Vision, Mission, including the College of Nursing Goals and Objectives of the Bataan Peninsula State University VMGO.

\section{Majority}

Table 1 presents the profiling of the respondents in terms of sex wherein majority are females with 81.25 percent while male participants are 18.75 percent. This implies that gender assertiveness must be considered in articulating the revision of the College Goals and Objectives including the Vision and Mission of the University. Representation of the participants as the stakeholders of the Bachelor of Science in Nursing were mostly students with 32.50 percent, seconded by the alumni with 22.95 and 22.18 percent are residents from the adopted communities. The recruitment of participant in this study was purposively chosen and able to consider the willingness to participate in the study. Recruited from the industry partners had good number of recruitment with 15.90 percent.

The employment data of the respondents referring to the alumni who have been recruited as sample of this study showed the current work status of the nursing graduates as relevant to their practice. The majority are employed. In their present occupation, most of the respondents assume professional work and the major line of business is in the health and social work sector. It was depicted that most of them are regular employees, have professional occupations and have local jobs in the health and social works [2]. Most of the respondents are regular/ permanently employed, only least is contractually and temporarily employed accordingly. Most of the respondents are locally employed. Thus, this implies the assessment on the awareness and acceptant to the impact on professional affiliations of nursing graduates in their goals and objectives of the college will realize to the transition of the vision and mission of the university.

This Table presents the frequency on how the respondents perceived the awareness in the VMGO of the University.

Table 2 presents the status of the stakeholders on they may perceived their level of awareness of the BPSU Vision and Mission and the College Goals and Objectives. The said presentation revealed that most of the alumni and industry partners are least aware to the BPSU VMGO than other stakeholders in terms of familiarity or verbatim articulated. Likewise, alumni, industry partners and some of the residents of the adopted communities are also least familiar with the college goals and objectives.

Hence, in terms of the participation to the formulation of the vision and mission, most were actively involved among students, university personnel and adopted communities resident. Likewise, alumni, industry partners were not able to participate [3].

This implies that the process of revision for the BPSU VM and College Goals and Objectives may further be revisited in order to ensure efficiency in the transition of changing the goals and objectives.

Table 3 presents the awareness of the BPSU VMGO among stakeholders in terms of medium used to disseminate information about it. Majority of the responses were geared about use of Facebook and BPSU Website and other means like Nursing Alumini Facebook and Student Council Facebook Account. Seconded to this were the Publications of the student organ. Also, Posters, other university officials and student handbook were considered in learning more about the VMGO.

Tables 4 and 5 reiterates the acceptance of the BPSU VMGO among stakeholders where revealed that in terms of consistency, the college goals and objectives of the college of nursing should be revisited in terms of the understanding of the students as they found it hard to accept though it got a total score of accepted. In addition, acceptance of the ideas for the VMGO, taking responsibility on the VMGO in reality toward practices, and its roles like in the day to day operations, curricular offerings, and performing their duties and responsibilities would assert their understanding to the VMGO as an important factor personally and professionally in engaging their works.

Findings of this study would drive a lot in the impact on the professional affiliations of the nursing graduates and their degree of awareness and acceptance to the College Goals and Objectives to traverse the realization of the University Vision and Mission. Part of the impact as participants were interviewed that they know the changes or transition in the VMGO as the curriculum change as well but one of the participants articulated "meron naman, alaman naman namen, kaso ang hirap din talaga, kasi alumni kame, wala ng continuous contact pero ung VMGO nuon inaapply namen sa work namen" while other participant ignited the statement given such as "sa community as adopted nila ng BPSU College of Nursing, in a apply sa ginagwa namen". These verbal responses could really qualify the intent for the dissemination of the VMGO and able to relate this to their day

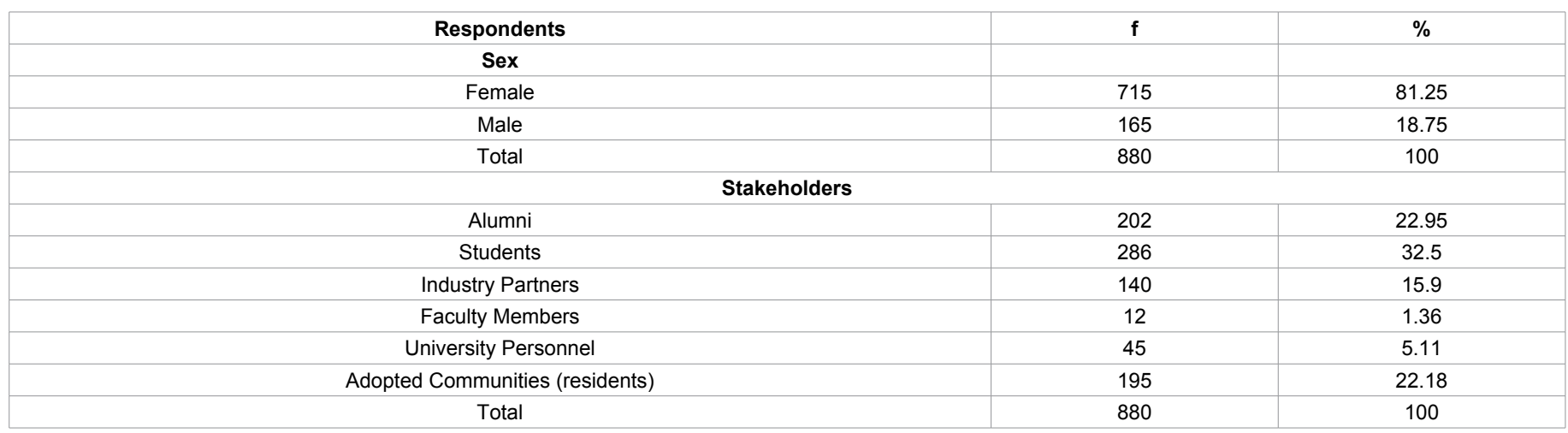

Table 1: Profile of the Respondents. 
Citation: Rosa RDD, Pantaleon NR (2018) Stakeholders' Level of Awareness and Acceptance of the Bataan Peninsula State University College of Nursing and Midwifery Goals and Objectives: Traversing to the Realization of the University's Vision and Mission. J Health Educ Res Dev 6: 280. doi: 10.4172/2380-5439.1000280

Page 3 of 4

\begin{tabular}{|c|c|c|c|c|c|c|c|c|c|c|c|c|}
\hline \multirow[b]{2}{*}{ Indicators } & \multicolumn{2}{|c|}{ Alumni } & \multicolumn{2}{|c|}{ Students } & \multicolumn{2}{|c|}{ Industry Partners } & \multicolumn{2}{|c|}{ Faculty Members } & \multicolumn{2}{|c|}{$\begin{array}{l}\text { University } \\
\text { Personnel }\end{array}$} & \multicolumn{2}{|c|}{ Adopted Communities } \\
\hline & Yes & No & Yes & No & Yes & No & Yes & No & Yes & No & Yes & No \\
\hline $\begin{array}{l}\text { 1. Are you familiar with the University's } \\
\text { Vision and Mission statements? }\end{array}$ & 22 & 180 & 281 & 5 & 34 & 106 & 10 & 2 & 45 & 0 & 175 & 20 \\
\hline $\begin{array}{l}\text { 2. Are you familiar with your college/ } \\
\text { office Goals and Objectives? }\end{array}$ & 12 & 190 & 276 & 11 & 34 & 106 & 10 & 2 & 22 & 23 & 101 & 94 \\
\hline $\begin{array}{l}\text { 3. Did you actively participate in the } \\
\text { formulation of the Vision and Mission? }\end{array}$ & 43 & 159 & 285 & 1 & 58 & 82 & 12 & 0 & 40 & 5 & 190 & 5 \\
\hline $\begin{array}{l}\text { 4. Did you actively participate in } \\
\text { the formulation of the Goals and } \\
\text { Objectives? }\end{array}$ & 41 & 161 & 285 & 1 & 58 & 82 & 12 & 0 & 14 & 31 & 190 & 5 \\
\hline $\begin{array}{l}\text { 5. Did you participate in any form of } \\
\text { orientation about the content and } \\
\text { meaning of the VMGO? }\end{array}$ & 102 & 100 & 286 & 0 & 135 & 5 & 12 & 0 & 40 & 5 & 180 & 15 \\
\hline Mean Scores & 220 & 790 & 992 & 18 & 629 & 381 & 1004 & 4 & 946 & 64 & 871 & 139 \\
\hline
\end{tabular}

Table 2: Awareness of the BPSU Vision and Mission/and College/Office Goals and Objectives.

\begin{tabular}{|c|c|c|c|}
\hline Medium & f & $\%$ & Rank \\
\hline Billboard & 12 & 0.86 & 8th \\
\hline Posters & 187 & 13.4 & 3rd \\
\hline Student Handbook & 166 & 11.97 & 5th \\
\hline BPSU Policy Manuals & 21 & 1.51 & 7th \\
\hline Flyers & 125 & 9.14 & 6th \\
\hline Publications (school organ) & 345 & 24.89 & 2nd \\
\hline Other University members & 165 & 11.9 & 4th \\
\hline Others (Facebook, BPSU Website) & 365 & 26.33 & 1 st \\
\hline Total & 1,386 & 100 & \\
\hline
\end{tabular}

Table 3: Awareness of the BPSU Vision and Mission/and College/Office Goals and Objectives among Stakeholders in terms of medium used to disseminate information about it.

\begin{tabular}{|c|c|c|c|c|c|c|}
\hline Indicators & Alumni/Rating & Students/Rating & $\begin{array}{c}\text { Industry Partners/ } \\
\text { Rating }\end{array}$ & $\begin{array}{l}\text { Faculty Members/ } \\
\text { Rating }\end{array}$ & \begin{tabular}{|c} 
University Personnel/ \\
Rating
\end{tabular} & $\begin{array}{c}\text { Adopted Communities/ } \\
\text { Rating }\end{array}$ \\
\hline $\begin{array}{l}\text { 1. I accept that the } \\
\text { ideas stated in the } \\
\text { Vision and Mission } \\
\text { are true and } \\
\text { important }\end{array}$ & $3.41 /$ Accepted & 3.50/ accepted & 3.52 /highly accepted & 3.72 /highly accepted & 3.54 /highly accepted & 3.50 /accepted \\
\hline $\begin{array}{l}\text { 2. The college/ } \\
\text { office Goals and } \\
\text { Objectives is } \\
\text { consistent }\end{array}$ & 3.33 /accepted & 2.45 /hardly accepted & 3.78 /highly accepted & 3. 56 /highly accepted & 3.02 /accepted & 3.20 /accepted \\
\hline $\begin{array}{c}\text { 3. I have a } \\
\text { responsibility in } \\
\text { making the VMGO } \\
\text { a reality }\end{array}$ & $\begin{array}{l}\text { 3. } 68 \text { /highly } \\
\text { accepted }\end{array}$ & 2.59 /accepted & 3.47 /accepted & 3.50 /accepted & 3.58 /highly accepted & 3. 50 /accepted \\
\hline $\begin{array}{l}\text { 4. Developing } \\
\text { a good moral } \\
\text { character is } \\
\text { important in making } \\
\text { the University's } \\
\text { VMGO a reality }\end{array}$ & 3.21 /accepted & 3.31 /accepted & 3.41 /accepted & 3.24 /accepted & 3. 44 /accepted & 3. 30 /accepted \\
\hline $\begin{array}{c}\text { 5. The VMGO } \\
\text { gives me focus and } \\
\text { direction in my daily } \\
\text { activities }\end{array}$ & 3.24 /accepted & 3.21 /accepted & 3.40 /accepted & 2.54 /accepted & 2. 94 /accepted & 3.10 /accepted \\
\hline $\begin{array}{l}\text { 6. The VMGO is } \\
\text { emphasized in the } \\
\text { curriculum and } \\
\text { services of the } \\
\text { University }\end{array}$ & 3.23 /accepted & 3.20 /accepted & 3.40 /accepted & 3.24 /accepted & 3.04 /accepted & 3.03 /accepted \\
\hline $\begin{array}{l}\text { 7. The VMGO is } \\
\text { being realized and } \\
\text { achieved in all } \\
\text { University activities } \\
\text { and undertakings }\end{array}$ & 3.14 /accepted & 3.51 /highly accepted & 3.44 /accepted & 2.54 /accepted & 2. 94 /accepted & 3.10 /accepted \\
\hline
\end{tabular}


Citation: Rosa RDD, Pantaleon NR (2018) Stakeholders' Level of Awareness and Acceptance of the Bataan Peninsula State University College of Nursing and Midwifery Goals and Objectives: Traversing to the Realization of the University's Vision and Mission. J Health Educ Res Dev 6: 280. doi: 10.4172/2380-5439.1000280

Page 4 of 4

\begin{tabular}{|c|c|c|c|c|c|c|}
\hline $\begin{array}{c}\text { 8. As a member of } \\
\text { the BPSU academic } \\
\text { community, I } \\
\text { perform my duties } \\
\text { and responsibilities } \\
\text { in consonance with } \\
\text { the VMGO }\end{array}$ & 2.83 /accepted & 3.20 /accepted & 3.48 /accepted & 3.49 /accepted & 3.34 /accepted & 3.43 /accepted \\
\hline Total & 3.25 /accepted & 3.12 /accepted & 3.15 /accepted & 3.63 /highly accepted & 3.23 /accepted & 3.27 /accepted \\
\hline
\end{tabular}

Table 4: Acceptance of the BPSU Vision and Mission/and College/Office Goals and Objectives among Alumni, Students, Industry Partners, Faculty Members, University Personnel, and Adopted Communities.

\begin{tabular}{|c|c|c|c|c|c|c|c|c|c|c|c|}
\hline & \multicolumn{2}{|c|}{ Alumni } & \multicolumn{2}{|c|}{ Students } & \multicolumn{2}{|c|}{ Industry Partners } & \multicolumn{3}{|c|}{ Faculty Members } & University Personnel & \multicolumn{2}{|c|}{ Adopted Communities } \\
\hline Indicators & Yes & No & Yes & No & Yes & No & Yes & No & Yes & No & Yes \\
\hline $\begin{array}{l}\text { 1. Do you believe that the } \\
\text { VMGO need to be revised }\end{array}$ & 192 & 20 & 283 & 3 & 114 & 26 & 12 & 0 & 40 & 4 \\
\hline
\end{tabular}

Table 5: Acceptance of the BPSU Vision and Mission/and College/Office Goals and Objectives among Employees and Students when asked to be revised.

to day routine as professionals and stakeholders of the College. The subjective responses driven from the content analysis of the interview will reassure that the VMGO of the College will conform to the need by the professional graduates in nursing practice and as well by the industry that they will be needed to [4].

The study recommends that continuous recruitment in the analysis of the stakeholders perspectives most especially the alumni as it has been established since 1990's that it must be routinely reviewed and strengthen the contact between alumni thru college activities like extensions and research works [5]. Likewise, students and faculty members must be able to experience in their learning in particular to their curriculum that the VMGO must be evident using the new framework of outcomes based education. For the industry partners, the job descriptions, duties and responsibilities sin incorporation this in their standards of work may be considered. University personnel especially the administrative department must give full support in the financial assistance to deploy this endeavor of disseminating strongly the college VMGO [6]. Lastly the adopted communities must be given a good avenue for them to well learn the VMGO and live with it. A focused group discussion may helpful to assert their knowledge.

\section{References}

1. College of Nursing and Midwifery (2009) Awareness and Acceptance of the Goals and Objectives of the College of Nursing and Midwifery of the Bataan Peninsula State University.

2. Department of Health (2014) Speech of Sec. Enrique T. Ona (First Global Summit of Filipino Nurses). Department of Health.

3. Paquiz LPG (2008) Philippine Nurses Association Demand Due Respect for the Worth and Dignity of Nursing Profession. Philippine Nurses Association, Inc.

4. Patton W, McMahon M (2014) Career development and systems theory: Connecting theory and practice. Springer, United States.

5. Philippine Daily Inquirer (2010) New Approach Needed

6. Philippine Statistics Authority (2016) Employment Rate in January 2016 is Estimated at 94.2 Percent. 